\title{
Relationship between Neck Length, Sleep, and Psychiatric Disorders: A Psychiatric Aspect
}

\author{
Cemil Celik*, Barbaros Ozdemir, Taner Oznur \\ Department of Psychiatry, Gulhane Military Medical Faculty, Ankara, Turkey
}

\section{Dear Editor,}

We read with great interest the article by Han and colleagues, entitled "Relationship between neck length, sleep, and cardiovascular risk factors," in which the investigators explored the association of neck length with sleep and cardiovascular risk factors by measuring midline neck length (MNL) and lateral neck length. They showed that a short neck, as measured by the MNL, is probably associated with snoring, and also that MNL is related to cardiovascular disease risk factors in women. ${ }^{1)}$ However, we believe that some points warrant discussion.

Sleep and psychiatric disorders are often concurrent, and untreated sleep disorders can increase the risk of developing psychiatric conditions. ${ }^{2,3)}$ The most common psychiatric disorders associated with sleep complaints include depression, anxiety, and substance (illicit drug and alcohol) abuse., ${ }^{3,4)}$

The researchers examined 240 patients aged 30 to 75 years who visited a health examination center. They excluded from the study patients with a history of depression or sleep disorders, or those currently on related medications. ${ }^{1)}$ However, many psychiatric disorders, including alcohol/substance use disorders, affect all parameters of sleep, mainly including sleep latency and total sleep time. ${ }^{3,4)}$ We believe that not only depression and sleep disorders, but also other psychiatric disorders, should have been excluded from the study.
The researchers indicated that sleep latency, total sleep time, and the number of apneas were identified by a self-reporting questionnaire in the study. ${ }^{1 .}$ However, specific sleep parameters, such as sleep latency and the number of apneas, can be determined accurately with polysomnography. ${ }^{5,6}$ Findings from a list of questions are subjective and may lead to misinterpretation. ${ }^{6}$

In conclusion, although this study contributes valuable information to the medical literature, clarifying these concerns will certainly provide a clearer picture.

\section{CONFLICT OF INTEREST}

No potential conflict of interest relevant to this article was reported.

\section{REFERENCES}

1. Han TS, Oh MK, Kim SM, Yang HJ, Lee BS, Park SY, et al. Relationship between neck length, sleep, and cardiovascular risk factors. Korean J Fam Med 2015;36:10-21.

2. Ford DE, Kamerow DB. Epidemiologic study of sleep disturbances and psychiatric disorders: an opportunity for prevention? JAMA 1989;262:1479-84.

3. McCall WV, Reboussin BA, Cohen W. Subjective measurement of insomnia and quality of life in depressed inpatients. J Sleep Res 2000;9:43-8.

4. Gierz M, Campbell SS, Gillin JC. Sleep disturbances in various nonaffective psychiatric disorders. Psychiatr Clin North Am 1987;10:565-81. 
5. Iber C, Ancoli-Israel S, Chesson AL Jr, Quan SF; American Academy of Sleep Medicine. The AASM manual for the scoring of sleep and associated events: rules, terminology and technical specifications. Westchester (IL): American Academy of Sleep Medicine; 2007.
6. Redline S, Budhiraja R, Kapur V, Marcus CL, Mateika JH, Mehra R, et al. The scoring of respiratory events in sleep: reliability and validity. J Clin Sleep Med 2007;3:169-200. 